\title{
Lima, el Magdaleno y los chilenos
}

\section{Lima, the La Magdalena government and the Chileans}

\section{Luis Guzmán Palomino}

Universidad Nacional de Educación Enrique Guzmán y Valle. Lima, Perú

luisguzmanpalomino@gmail.com

\section{RESUMEN}

Ocupada Lima por el Ejército chileno y puesto en fuga el dictador Nicolás de Piérola, emerge un Gobierno de «notables» en la capital, bajo la presidencia de Francisco García Calderón. Cuenta este con la anuencia de Chile, porque se cree que aceptará la paz con la cesión de Tarapacá. Pero el nuevo mandatario, que representa al grupo peruano interesado en el salitre, realmente busca preservar esa riqueza. Se esperanza en la intervención norteamericana y negocia con el Crédit Industriel de Francia un empréstito que condujera a la obtención de la paz a cambio de una crecida indemnización. A la vez, paga un considerable cupo al invasor valiéndose de un préstamo e incrementa así la deuda interna peruana. El examen de algunos de sus discursos lo revela como líder de la clase dominante. Considera "ciudadanos» a los miembros de su grupo y toma distancia del "pueblo trabajador», aunque le exige apoyo a cambio de retornar al «orden». Esto supone terminar con la resistencia que ha surgido allende la cordillera, pero fracasa en ello estrepitosamente. A la postre, el alto mando chileno entiende que García Calderón no sirve a sus intereses, al tiempo que descubre la trama secreta sobre el salitre de Tarapacá y pone entonces fin a la farsa de La Magdalena. Parte de la información sobre estos hechos procede de la prensa coetánea, peruana y extranjera.

1 Magíster. Profesor de Historia en la Universidad Nacional de Educación Enrique Guzmán y Valle. Sobre el conflicto de 1879-1884 ha publicado: Compendio histórico de la guerra con Chile; Crónica de la Guerra del Pacífico; Diario de la Guerra del Pacífico; Los héroes de la Breña; Campaña de la Breña. La contraofensiva de 1882; Campaña de la Breña. Huamachuco y el alma nacional; Cáceres, conductor nacional; La crónica francesa de la Breña; Guerra de razas y comuna en la campaña de la Breña; Campaña de La Breña. Colección de documentos inéditos 18811884; Las guerrillas de Canta y Huarochirí en la campaña de la Breña; Historia del heroísmo de los pueblos del Mantaro en la campaña de la Breña; Cáceres: la otra historia de la Breña; Cáceres y la Breña. Compendio histórico y colección documental y La primera memoria de Cáceres y otros documentos relativos a la campaña de la Breña. 


\section{PALABRAS CLAVE}

Guerra del Pacífico, salitre, diplomacia norteamericana, Francisco García Calderón, resistencia, Andrés Cáceres

\section{ABSTRACT}

With Lima occupied by the Chilean army and the dictator Nicolás de Piérola on the run, a government of «notables» emerged in Lima, under the presidency of Francisco García Calderón. This government received the support of Chile, because it was believed that it would accept peace and the ceding of Tarapacá. But the new president, as a representative of those Peruvians with an interest in saltpeter, sought to hold on to that wealth. He placed his hope in US intervention and negotiated with France's Crédit Industriel a loan through which he would be able to sue for peace in exchange for massive compensation. At the same time, he paid a considerable sum to the invader, thereby increasing Peru's internal debt. Studies of some of his speeches reveal him to be a leader from the ruling class. He considered those from his own class «citizens» and distanced himself from the «working class», while at the same time calling for their support in exchange for "a return to order». This supposed an end to the resistance movement which had spread beyond the highlands, a demand destined to fail resoundingly. Eventually, the Chilean high command saw that García Calderón did not serve their interests, and at the same time the secret Tarapacá saltpeter deal was uncovered, and the La Magdalena farce was brought to an end. Part of the information contained in this article is taken from the Peruvian and foreign presses of the time.

\section{KEYWORDS}

War of the Pacific, nitrates, American diplomacy, Francisco García Calderón, resistance, Andrés Cáceres

La derrota militar de Piérola en Lima y su precipitada fuga al interior fue aprovechada por sus rivales políticos para formar un nuevo Gobierno, complaciendo las exigencias del general Baquedano, jefe del ejército de ocupación. En principio, este lo demandó del alcalde de Lima, Rufino Torrico, quien convocó una junta de notables sin llegar al término requerido. Aunque servil ante los chilenos, el alcalde no pudo ser desleal a Piérola, y por ello convocó solo a los adictos a su partido, con tal resultado. No pudiendo obtener nada más del alcalde, Baquedano trasladó la sugerencia 
de formar un nuevo Gobierno a otros líderes políticos y a los oportunistas de toda hora, y se verificaron entonces varias juntas promovidas por el general La Cotera, Dionisio Derteano y Mariano Felipe Paz Soldán. En ellas predominó el parecer del civilismo, que sin discusiones acordó el derrocamiento de Piérola, esto es, el fin de la dictadura. En un principio se pretendió la restauración del Gobierno que existiera antes del golpe de Estado de 1879, con el general Luis La Puerta como presidente constitucional; pero este se negó terminantemente a todo compromiso, simple y llanamente por falta de decisión. A consecuencia de ello, surgió con fuerza la candidatura de Francisco García Calderón, jurisconsulto de fama entre cuyos antecedentes podría citarse el haber pugnado en 1867 porque se mantuviese la contribución personal que pesaba sobre los indígenas, el haber conspirado desde la presidencia del Congreso contra el presidente Prado, su fracaso como ministro de Hacienda de Balta en 1868, el haber promovido el estanco «estatal» del salitre en 1873 y el haber sido nombrado en 1876 presidente de la Compañía Salitrera del Perú, formada por la plutocracia guanera transformada en banquera, que asumió la totalidad del negocio salitrero. La pretendida «estatización» fue hecha a favor de los bancos acreedores del fisco, que en 1878 cedieron sus derechos al banco La Providencia².

El 22 de febrero de 1881, en junta presidida por Aurelio Denegri, poco más de cien «notables» de la capital, en su mayoría civilistas, eligieron a García Calderón presidente provisorio de la República. Se presentaron también las candidaturas del propio Denegri, la de Antonio Arenas y la del ausente Lizardo Montero, que obtuvieron votación minoritaria. Repárese que los civilistas tomaron en cuenta a Montero, pese a que este había aceptado el encargo de Piérola de asumir la jefatura política y militar de los departamentos del norte. El diario chileno La Actualidad informó pormenorizadamente sobre el desarrollo del acto eleccionario y consignó que García Calderón obtuvo la victoria «casi por unanimidad» en una votación secreta que solo registró a 114 electores. Al agradecer a los «notables» tal apoyo, y considerarlo como la voluntad de todo el país - tremenda pretensión-, el flamante presidente provisorio recordó:

que al decir en la víspera que era una infeliz víctima el individuo sobre cuyos hombros iba el país a echar la carga del Gobierno, lejos estaba de pensar que esa víctima era él; pero que al ser designado por la parte más notable del pueblo de Lima, sin haber solicitado ni pedido sus sufragios, no omitiría sacrificio alguno para corresponder a la confianza que se le hacía y salvar al Perú de la situación actual y

2 Los pormenores de este negocio pueden revisarse en Compañía Salitrera del Perú (1912). 
de sus múltiples exigencias, en la inteligencia de que él se proponía gobernar con todos, o mejor dicho, que el pueblo, por su órgano, gobernaría (La Actualidad, 23 de febrero de 1881).

Demagogia pura, con una retahíla de lugares comunes, promesas que no pasaban de ser eso, farsa de democracia propia de un país anárquico, en la que algo más de cien señorones, a requerimiento y con apoyo del invasor extranjero, eligieron a uno de ellos para defender no los intereses de los millones de peruanos, sino los de su grupo económico. En esto los chilenos fueron sorprendidos, pues en principio creyeron haber formado un Gobierno títere que sin más aceptaría la paz con cesión territorial. Fue con este equivocado convencimiento que los plenipotenciarios chilenos, señores Juan Francisco Vergara y Eulogio Altamirano, dieron su visto bueno al nuevo régimen, y hasta ofrecieron en privado entregar al flamante Gobierno la ciudad de Lima y las entradas de la aduana de Ancón, y se reservaron ocupar el Callao militarmente mientras se firmaba la paz definitiva, sin perjuicio de acordar un armisticio a fin de facilitar la consolidación del nuevo Gobierno con las adhesiones de los pueblos (Buenaventura Seoane, 1903, p. 83). Pero a cambio de ello exigieron la inmediata negociación del tratado de paz, sin variar sus apetencias respecto al territorio del guano y del salitre, a lo que García Calderón se negó con calculada cortesía, aduciendo que le era preciso reunir previamente al Congreso. Los chilenos retiraron entonces el citado ofrecimiento y se limitaron a declarar como territorio neutral el caserío de La Magdalena, donde el 12 de marzo se instaló con toda pompa el Gobierno provisorio. Una correspondencia española daría este detalle:

Se ha establecido ya un Gobierno provisional que reside en Magdalena, donde flamea el pabellón peruano en virtud de arreglo con los chilenos. Esa población se halla a dos millas de Lima; ha sido lugar de temporada desde que los virreyes primero y después Bolívar la escogieron como residencia campestre. El pueblo ocupa una posición preciosa; está rodeado de huertos bien cultivados, pero su aspecto no corresponde al rango de capital. El día 12 quedó instalado el Gobierno en presencia de gran número de personas que salieron de Lima a las ceremonias de inauguración y a demostrar que están resueltas a sostener el orden de cosas que ha surgido de los acontecimientos $^{3}$.

En esa misma correspondencia se anotó que las ciudades de Trujillo y Huancavelica fueron las primeras en adherirse al nuevo régimen y que

3 Fechada en Lima el 31 de marzo de 1881 y publicada en La lberia de Madrid, el martes 10 de mayo de 1881. 
si tardaban en llegar adhesiones del resto del país era porque la trababa la burocracia pierolista de provincia que quería mantenerse en sus cargos: «Si no fuera por la presión que ejercen las autoridades y empleados esparcidos por el país, deseosos de retener sus destinos, no habría ciudad ni aldea que no votara por el señor García Calderón con el objeto de obtener la paz» ${ }^{4}$. Aseveraciones casi todas absolutamente alejadas de la verdad, sobre todo por la mención a Huancavelica, porque en vez de adhesiones lo que llegó del interior del país fue una protesta generalizada, no solo con cientos de pronunciamientos de cabildos con miles de firmas que exigían la prosecución de la guerra, creyendo en el mensaje demagógico de Piérola, sino, lo que es más importante, con la patriótica condena de los que en el interior presentaban ya resistencia armada al invasor.

\section{Condena nacional al Gobierno de La Magdalena}

El presidente provisorio escribió a sus amigos y a personas influyentes de diversas provincias del interior solicitándoles reconocimiento y apoyo. Obtuvo escasas adhesiones, apenas unas actas suscritas por algunos notables del Callao, Trujillo, Huancabamba, Lircay y Contumazá, lo que dio a luz El Orden. Circularon, por el contrario, numerosos documentos condenatorios; figuraron entre los más severos aquellos que, procedentes de numerosos pueblos del Centro, publicó en sucesivas entregas el Registro Oficial de Junín, entre febrero y mayo de 1881. Casi todos coincidieron en declarar traidores a la patria a los partidarios de La Magdalena, por servir los intereses chilenos; y al declarar su fidelidad al régimen dictatorial, volvieron a demandar para Piérola el ascenso a general de brigada.

Cabe aquí un paréntesis para hacer referencia a una asonada que tuvo por escenario la villa de Lircay, Huancavelica, donde inmediatamente después de conocerse el desastre de Lima hubo un intento de desconocer a las autoridades constituidas, movimiento que con adversa suerte encabezó el coronel Nicolás Navarro. Se desconoce cuáles fueron sus miras y motivos, y por la fecha de su fallido golpe parece que no estuvo en relación con los que en Lima discutían por esos días la posibilidad de formar un nuevo Gobierno. Solo 10 días después de la toma de Lima por los chilenos, esto es, el 27 de enero de 1881, precisamente a raíz de esa asonada, se reunió en comicios la ciudadanía de la villa de Acobamba, antigua capital de la provincia de Angaraes, para pronunciarse a favor de proseguir la guerra contra Chile.

Aun desde antes de la elección de García Calderón se había sabido en el centro de la república que la oligarquía limeña estaba en tratos con

4 Ídem. 
los chilenos. Lo prueba, además de lo citado, el que tan tempranamente como el 4 de febrero tuviese lugar una manifestación popular en la plaza principal de Chincheros, cabecera del distrito del mismo nombre en la lejana provincia de Andahuaylas, cuyos pobladores, convocados por el párroco doctor José Manuel Sánchez, acordaron:

desconocer toda medida que tienda en desprestigio de la autonomía e integridad nacional; ofrecer sus servicios al Supremo Jefe de la Nación, doctor don Nicolás de Piérola, como al único que puede sostener con honor e incólumes las banderas nacionales; (y) ofrecer, por último, nuestros servicios, hasta perder la última gota de sangre en aras de la patria, bajo la dirección del ínclito jefe nacional (Registro Oficial de Junín, viernes 18 de marzo de 1881).

¡Cuán lejos de la realidad estaban los chilenos y los calderonianos cuando creyeron que ya no era posible la resistencia armada! Allí estaban los pueblos del centro decididos a ofrecer una vez más su cuota de sangre para rechazar al invasor extranjero. Pueblos que solo se equivocaron al creer que Piérola se pondría a la cabeza de la resistencia patriota. Las actas elevadas por los vecinos de Concepción, Huancayo y Sicaya, Sapallanga, San Jerónimo y Chupaca, el 14, el 16, el 19 y el 20 de febrero, respectivamente, con muy parecido tenor, consideraron como un crimen de lesa patria el desconocimiento del Gobierno de Piérola y tomaron el acuerdo de «declarar traidores a todos los que, bajo la presión del enemigo, desconocieren el Gobierno del actual jefe supremo de la república, o sirvieran de dóciles instrumentos para introducir cualquier cambio en la administración nacional» (Registro Oficial de Junín, viernes 25 de febrero de 1881).

El pueblo de Huancavelica se pronunció el 18 de febrero, «considerando un ataque a la soberanía nacional la intervención que los agentes del Gobierno de Chile pretendieran tomar en asuntos internos del Perú, desconociendo su Gobierno o intentando cambiarlo, prevalidos de las fuerzas que ocupan la capital de la república»; en razón de lo cual acordaron «declarar traidores a la patria a los que, bajo la presión del enemigo, sirvan de instrumento o den sus nombres para cualquier cambio en la administración nacional» (Registro Oficial de Junín, viernes 4 de marzo de 1881). La ciudadanía de Chongos, el 20 de febrero, introdujo una variante, al «declarar traidores a todos los que sirvieren directamente a las intenciones de Chile, desconociendo al Gobierno del actual jefe supremo de la república» (Registro Oficial de Junín, miércoles 2 de marzo de 1881).

Los vecinos de la ciudad de Tarma fueron más cautos. En Acta firmada el 21 de febrero, simplemente acordaron: «No reconocer otro Gobierno que el del excelentísimo señor don Nicolás de Piérola, el mismo que aún sigue mereciendo la confianza del país y el único que tiene el derecho de 
representarlo» (Registro Oficial de Junín, miércoles 2 de marzo de 1881). El subprefecto José María Alvariño, que elevó este documento al jefe superior político y militar del centro, estaba ya comprometido con los civilistas y solo esperaba la retirada de Piérola para pronunciarse en Tarma a favor de García Calderón, en acción coordinada con los potentados de Jauja y Cerro de Pasco. Pero los vecinos de Chacapalca sí que fueron contundentes, pues uno de los considerandos del Acta que suscribieron el 22 de febrero, decía a la letra: «cualquiera que sea investido del poder por las bayonetas extranjeras, contrariando al Gobierno del jefe supremo, no podrá significar otra cosa que la abyección más absoluta y revelar un espíritu completamente opuesto a los sentimientos y dignidad del Perú» (Registro Oficial de Junín, miércoles 2 de marzo de 1881).

Ese mismo día, los pobladores de la villa de Acobamba, comprensión de la provincia de Tarma, acordaron «desconocer todas las medidas y resoluciones que tome el ejército invasor respecto a forma de gobierno» $y$ «declarar traidores a la patria a los que pretendan o consigan subrogar en el mando supremo al actual jefe de Estado, o se sometan a las disposiciones de las autoridades chilenas» (Registro Oficial de Junín, viernes 18 de marzo de 1881). También el 22 de febrero, reunidos en asamblea, los vecinos del asiento mineral de San Antonio de Yauli se declararon a favor de continuar la guerra. Y considerando «que cualquier individuo, ya civil, ya militar, que pretendiese ser revestido de la autoridad suprema, apoyado con la fuerza de las armas chilenas [...] no haría otra cosa que una irregularidad a los sentimientos y bienestar del Perú», resolvieron declarar traidores a la patria «a los que coadyuven directa e indirectamente al decaimiento de la patria, declarándoseles fuera de la ley» (Registro Oficial de Junín, viernes 11 de marzo de 1881).

Por ironía del destino, ese mismo 22 de febrero un centenar de señorones de Lima, acatando la voluntad del alto mando chileno y con la protección de las tropas que ocupaban la capital de la república, ungían a Francisco García Calderón como nuevo mandatario del Perú, agravando la crisis interna, como queda dicho. Un día antes se habían pronunciado los habitantes de Colca y concluyeron «que los que presten el apoyo de sus nombres o personas para que las autoridades chilenas desconozcan el Gobierno, infiriendo un ataque a la autonomía e independencia nacional, deben ser considerados traidores a la patria» (Registro Oficial de Junín, viernes 11 de marzo de 1881). Los vecinos de Huanta, en Acta firmada también el 21 de febrero, acordaron declarar «traidores a los que bajo la presión del enemigo sirviesen de instrumentos o prestasen sus nombres para cualquier cambio en la administración nacional» (Registro Oficial de Junín, viernes 18 de marzo de 1881). Tres días después, los pobladores 
de Carhuamayo, tras señalar que la ocupación chilena de Lima no había puesto fin a la guerra, acordaron «declarar nulos y de ningún valor los actos gubernativos de los invasores; declarando, asimismo, traidores a la patria a los peruanos que se adhieran a ellos, o de algún modo intenten suplantar al Gobierno del excelentísimo señor Piérola» (Registro Oficial de Junín, viernes 18 de marzo de 1881). Los de Ayacucho lo hicieron el 25 de febrero, declarando «traidores a la patria a los que, bajo la presión del enemigo, desconozcan al Gobierno constituido en enero de 1880 y reconocido por todas las potencias del mundo» (Registro Oficial de Junín, viernes 18 de marzo de 1881).

Singularmente importante lo sucedido el 26 de febrero en la sierra de Lima, porque demuestra que en fecha tan temprana estaban ya organizadas las columnas de guerrilleros en Huarochirí. Por esos lares actuaba entonces el coronel José Agustín Bedoya, a quien debe considerarse como precursor o iniciador de la campaña de La Breña, conjuntamente con el teniente coronel Francisco B. Segura y los párrocos Francisco M. Cabrera e Hilario Gómez. Todos ellos estuvieron siempre al tanto de lo que ocurría en Lima, pues al campamento guerrillero llegaban puntualmente los periódicos que allí se editaban. Y fue precisamente en respuesta a lo publicado por La Actualidad, que aquel día suscribieron el patriótico pronunciamiento que a continuación copiamos:

En el campamento de San Jerónimo, a los 26 días del mes de febrero de 1881: los jefes, oficiales y tropa pertenecientes a las Columnas de Guerrilleros de los distritos que comprende la sección de la derecha, presididos por su comandante militar, teniente coronel don Juan B. Segura, se reunieron con motivo de haberse impuesto de varios documentos que publica el periódico de Lima La Actualidad, cuyos documentos revelan que una pequeña porción de malos ciudadanos se ha ocupado de nombrar un presidente provisorio para la república, desconociendo la autoridad de S. E. el jefe supremo, que todos los pueblos aceptaron y reconocieron desde el 21 de diciembre del año antepasado de 1879.

Teniendo en consideración: Que nadie tiene facultad de imponer al país un nuevo Gobierno sobre el que tiene unánimemente aceptado y reconocido, al cual están obligados todos los peruanos a respetar y obedecer, debiendo por lo tanto de calificarse semejante acto como un ataque a la soberanía de la nación; que la reunión de los firmantes del acta de la elección del 23 del presente revela que esos ciudadanos han procedido o bajo la presión de las fuerzas chilenas que hoy ocupan la capital de Lima o en virtud de criminales connivencias con los representantes de ese ejército, para disponer con libertad de la suerte y caudales del país; lo cual queda suficientemente comprobado con el hecho de no haberse aceptado a los comisionados 
competentemente autorizados por el jefe supremo, única autoridad que ha podido nombrarlos con perfecto derecho; y que una diminuta fracción de individuos, nada significa ante la gran mayoría de ciudadanos patriotas que forman la comunidad de la república, y que por lo mismo debe rechazarse con energía tan arbitrario procedimiento.

Acordaron: Protestar, como en efecto protestan, de todos los actos practicados en Lima por esos ciento catorce individuos que suscribieron el acta, a los que declaran como traidores a la patria, y ofrecer apoyar la autoridad de S. E. el jefe supremo actual, doctor don Nicolás de Piérola, hasta que se hagan las negociaciones de paz y se convoque por él únicamente un Congreso Constituyente, si es que no hubiese necesidad de continuar la guerra, debiéndose remitir copia de la presente a la Municipalidad de Lima y a S. E. el jefe supremo (Registro Oficial de Junín, sábado 2 de abril de 1881).

La reacción en el sur fue algo más tardía. Todo parece indicar que en Arequipa el pueblo presionó a sus autoridades para que se pronunciasen contra García Calderón, y es muy probable que esto contrariase el parecer de los potentados de la región, en especial los latifundistas, laneros y grandes comerciantes, cuyos pensamientos eran afines a los de la oligarquía limeña y cuya nefasta influencia tuvo que ver en la ambivalente conducta que habrían de mostrar en todo momento sus autoridades civiles y militares. Una hoja impresa el 12 de marzo dio a entender que en los días previos y en varias reuniones, ciudadanos representativos deliberaron sobre la nueva situación y decidieron convocar al pueblo para el domingo 13, en la plaza de Armas, a fin de que manifestase su soberana voluntad. Firmaron el documento los señores Morales Alpaca, Adolfo Valdez, F. Santiago Corrales, Rubén Bustamante, Vicente Franco y Manuel Rosas. Una proclama contenida en esa hoja condenó el proceder de García Calderón, quien «prescindiendo de los invulnerables derechos que constituyen nuestra nacionalidad, pretende imponer al Perú un tratado afrentoso que satisfaga la insaciable voracidad de Chile» ${ }^{5}$. La manifestación popular fue celebrada y al término de ella se suscribió en un acta popular las siguientes resoluciones:

Que (Arequipa) mira como ofensiva a su dignidad, y con indignación y desprecio, aquella parodia de Gobierno provisional, elegido por 114 individuos de la ciudad de Lima, que hoy ocupa el invasor extranjero; que el Gobierno presidido por el doctor don Nicolás de

5 Esta hoja impresa fue publicada por Zoila Aurora Cáceres en su obra citada, pp. CX-CXI. Constituye un testimonio de la prensa informal, al igual que la hoja impresa que los plutócratas hicieron circular en Lima en febrero del mismo año. 
Piérola continúe sin descanso ni tregua la guerra contra Chile, hasta alcanzar la vindicación nacional y una paz tan honrosa como segura; que con lealtad inquebrantable se lleve adelante la Alianza Perú-Boliviana y se cumpla el Pacto Federal; y que para los fines presentados, Arequipa apoya al Gobierno con el celoso cumplimiento de sus deberes, llegando hasta el sacrificio, si necesario fuese (Registro Oficial de Junín, sábado 2 de abril de 1881).

Por su posición territorial, los arequipeños anhelaban la renovación del pacto con Bolivia, y el propio Piérola, poco después, trabajaría en ese sentido. Vana esperanza, sin embargo, porque en el país altiplánico había ganado terreno la posición entreguista y de allá no vendría ya ningún apoyo efectivo al Perú. Horas antes del citado mitin, se había reunido el ejército para ser revistado por el doctor y coronel Pedro Alejandrino del Solar, jefe superior político y militar de los departamentos del sur, quien tomó la palabra haciendo ver a sus jefes y oficiales que era necesario que el ejército fuese el primero en manifestar al país que no solo desconocía al Gobierno de García Calderón, sino que estaba resuelto a continuar la guerra sin tregua (Registro Oficial de Junín, sábado 2 de abril de 1881). De manera unánime los allí presentes aprobaron ese parecer y se redactó el acta respectiva con los siguientes acuerdos:

1. Declarar terminante y perentoriamente que desconocen al Gobierno provisorio inaugurado en Lima, bajo la presidencia del doctor don Francisco García Calderón. 2. Continuar la guerra, sin tregua y sin descanso, como y donde mejor convenga, hasta alcanzar una paz verdaderamente honrosa para el Perú. 3. Prestar al jefe supremo de la República, señor don Nicolás de Piérola, todo el apoyo y cooperación que demanda el patriotismo en las presentes circunstancias (Registro Oficial de Junín, sábado 2 de abril de 1881).

Ese mismo 13 de marzo, Del Solar expidió un decreto denunciando al Gobierno provisorio por «delito de rebelión» y calificando de «traidores a la patria» a sus integrantes y a todos los que le obedeciesen o prestasen apoyo directo o indirecto, al tiempo que ordenaba a las autoridades de su jurisdicción la captura de esos individuos, cualquiera que fuese su clase, jerarquía o condición, para su enjuiciamiento sumario en consejo de guerra verbal y su consecuente ejecución, en conformidad con las leyes vigentes. $Y$ además protestó por el acto de fuerza consumado en Chala, puerto del que se apoderaron los calderonianos «con una partida de hombres armados salidos del Callao, a la vista y con el consentimiento de los chilenos» (citado por Cáceres, op. cit., cap. 3, anexo 43). El coronel Velarde, ministro de Gobierno del régimen de La Magdalena, deploró tal proceder y cursó a Del Solar un oficio señalando que solo una «pequeña parte del pueblo» podía secundar aquella declaración, pues la mayoría 
aprobaba lo actuado en Lima, exhortándolo a rectificarse y adherirse a García Calderón (citado por Cáceres, op. cit., cap. 3, anexo 43), lo que provocó una respuesta más contundente:

No soy yo ni las personas que me rodean —escribió Del Solar-, quienes queremos disponer de la suerte del Perú, como dice V. E., sino lo son quienes contra la voluntad del Perú y por medios que el honor y la dignidad rechazan, han levantado la bandera de la anarquía, no solo frente al enemigo de la patria sino bajo su protección y amparo. Los que han provocado la guerra intestina para llegar por ella a una paz, a todo evento, que les permita recuperar lo que la guerra les ha hecho perder, esos son los que intentan disponer de la suerte del Perú en provecho propio... Doy por toda respuesta: guerra sin tregua al enemigo exterior, como único medio de alcanzar una paz honrosa (y) castigo ejemplar a los traidores que deshonran a su patria (Cáceres, op. cit., p. 140).

Del Solar fue un intelectual de prestigio, catedrático de ciencias, abogado, parlamentario y periodista, redactor del diario La Patria y organizador de una Columna de Tipógrafos de la Guardia Urbana. En abril de 1881 viajó a Bolivia y fue recibido por sus más altas autoridades, pero poco pudo hacer por reanimar la alianza con ese país que al igual que el nuestro estaba anarquizado. Partidario de continuar la resistencia al invasor, no tuvo empero la capacidad de organizarla y se mantuvo en una inacción semejante a la de Piérola en Ayacucho. Así, solo unos meses después sería derrocado.

Una manifestación similar tuvo lugar en Puno, encabezada por el prefecto teniente coronel Julio Jiménez, y acordó el 13 de marzo «desconocer todo Gobierno que no emane de la voluntad nacional y, en consecuencia, al Gobierno de García Calderón»; sostener al encabezado por Piérola, «reconocido por todos los pueblos del Perú y potencias extranjeras», y ofrecer «todo el contingente necesario para continuar la guerra sin tregua contra Chile, hasta obtener una paz honrosa o sucumbir en la lucha agotando la sangre y los recursos del departamento» (Registro Oficial de Junín, martes 5 de abril de 1881). El 17 de marzo la ciudadanía de Chincha resolvió adherirse a los pronunciamientos del sur, apoyando «la continuación de la guerra y la alianza con nuestra hermana la República de Bolivia» y reiterando su confianza en Piérola, «el único que estamos dispuestos a sostener y acompañar aun con el sacrificio de nuestras vidas e intereses para salvar a la patria de sus enemigos internos y externos» (Registro Oficial de Junín, martes 5 de abril de 1881). Pero la más importante reacción se produjo en Áncash, cuyo prefecto Tadeo Terry, respondiendo a la carta que García Calderón le remitiera el 22 de marzo, consignó estas expresivas líneas: 
Nos habla usted de nuestra absoluta impotencia y de la ruina de la fortuna privada. En cuanto a lo primero, no pienso como usted; tenemos algunos elementos y podremos obtenerlos, lo que nos falta es cohesión y unidad de ideas, un solo pensamiento para salvar a la patria de la postración a la que nosotros mismos la hemos conducido con nuestros procedimientos del pasado. Un pueblo vencido hoy puede levantarse y puede ser fuerte y vencedor mañana, si nosotros con ánimo resuelto, separándonos de las intrigas de partidos, nos reorganizamos al amparo de las fuerzas del sur y del patriotismo leal. Podemos combatir al enemigo y escarmentarlos. Este será el final de la contienda (citado por Herrera, 1997, p. 253).

Deploró Terry que García Calderón se humillase ante Chile con deshonra: «Que acaben los chilenos de esgrimir su saña; que cumplan sus satánicos propósitos de destruir nuestros valiosos fundos y edificios; pero que no consigan humillar nuestro decoro y dignidad» (citado por Cáceres, 1921, p. 140). Tamaña condena provocó las iras del Magdaleno al punto que las primeras tropas que pudo organizar con apoyo chileno recibieron por misión acallar la protesta de Áncash. Importante es notar que los juicios vertidos por Terry, respecto a la esperanza en revertir el resultado de la guerra, y sobre la necesidad de superar las pugnas partidarias para forjar la unidad nacional, coincidieron con el parecer que luego haría público el general Cáceres.

Una actitud muy distinta asumió por su parte Lizardo Montero, el jefe superior político y militar de los departamentos del norte, cuya adhesión había sido solicitada por el ministro Velarde. Le respondió en términos corteses, «sintiendo sobremanera la imposibilidad de acceder a las indicaciones de V. S.» ${ }^{6}$. A la sazón, Montero se hallaba en Yonán, hacienda inmediata a Cajamarca, preocupado en ordenar a sus lugartenientes que captasen erogaciones «destinadas a satisfacer los gastos de guerra» ${ }^{7}$. La forma en que este jefe entendía la guerra era sumamente peculiar, mas de cualquier forma le generaba gastos, sobre todo para cumplir con el pago de sueldos. Coincidiendo con el rechazo de Montero a la propuesta de García Calderón, los chilenos impusieran un cupo de 100000 soles de plata a la ciudad de Trujillo, pese al acta que firmaron sus notables adhiriéndose al Gobierno provisorio. Ello provocó un gran desconcierto y en Pacasmayo hubo un intento sedicioso, que fue contenido por el comandante Eduardo Dávila. Pacasmayo era un puesto de

6 Carta al ministro de Gobierno, Yonán, 14 de marzo de 1881, publicada por Cáceres, op. cit., cap. 3, anexo 36.

7 Carta de Montero al teniente coronel Julio Octavio Reyes, Cajamarca, 7 de marzo de 1881, publicada por Cáceres, op. cit., cap. 5, anexo 35. 
importancia pues allí funcionaba la aduana cuyos fondos se remitían a Montero $^{8}$.

En un desesperado afán por demostrar a los chilenos alguna efectividad, García Calderón decretó el 18 de marzo el cese de las autoridades municipales nombradas por Piérola, declaró sin ningún valor todo lo actuado por los cabildos desde el golpe de diciembre de 1879 y ordenó reasumir los cargos a los que entonces lo habían ejercido. Fácilmente se aprecia que era una medida simbólica, que solo podía cumplirse en la capital ocupada e incluso en ella hubo alguna resistencia del alcalde Torrico, quien cesó en su pírrica protesta al amenazársele con un juicio de persistir en su negativa. Describiendo esa conducta, Ricardo Palma informó a Piérola:

Rufino Torrico, después de firmar la enérgica protesta que usted conocerá ya — del 29 de marzo—, salió haciendo lo que llamamos los criollos «carrera de caballos, parada de borrico». ¡Guapo señor Torrico! Todo estaba combinado para que la farsa calderoniana recibiera el golpe de gracia cayendo en medio de la rechifla popular y sin quemarse un gramo de pólvora. Pero don Rufino y don Francisco se entendieron y la argolla salvó del conflicto?.

En reemplazo de Torrico y a propuesta del señor Graña, fue nombrado nuevo alcalde de Lima el coronel César Canevaro, otro ambicioso de polendas. Comentando este suceso, un anónimo de Lima escribió a Piérola:

Parece que Canevaro está resentido; según unos porque no lo han hecho general y según otros porque no le han escrito llamándole a tu lado. Sea de ello lo que fuere, lo cierto es que ha aceptado el cargo de alcalde de la municipalidad reaccionaria, a despecho de la dignidad y del honor que le prescribían, por lo menos, una actitud prescindible. Graña, el sempiterno intrigante y que es el mentor de Canevaro, ha sido quien ha persuadido a su pupilo que debía aceptar ese puesto ${ }^{10}$.

Era entonces Canevaro un joven coronel, de solo 35 años de edad, no obstante lo cual tenía ya una experimentada carrera pública. Hizo su formación militar en Francia, donde estuvo desde los 10 años. Era miembro de una familia de una gran solvencia económica, que labró su riqueza, entre otras cosas, con la trata de los semiesclavos culíes. Al volver Canevaro al Perú en 1870, no se incorporó al Ejército, sino que se dedicó al comercio y a las finanzas, y alcanzó la gerencia del Banco del Perú. Su cuantiosa

8 Oficio del comandante Eduardo Dávila al jefe político y militar de los departamentos del norte, dechado en Ascope el 15 de marzo de 1881, publicado por Cáceres, op. cit., pp. 132133.

9 Carta fechada en Lima el 4 de abril de 1881, en Palma, 1979, p. 34.

10 Carta fechada en Lima el 4 de abril de 1881. Biblioteca Nacional. Archivo Piérola, caja 59. 
fortuna le permitió ser propietario de los diarios El Nacional y La República. Se adhirió prontamente al partido civilista y fue designado jefe de la guardia nacional por el presidente Pardo. En 1874 le tocó debelar la insurrección pierolista que estalló en Moquegua. Al declararse la guerra con Chile viajó a Panamá, comisionado para la adquisición de armamento, y al regresar fue destinado al frente sur, asumiendo la comandancia general de la segunda división del ejército comandado por Montero. En tal calidad concurrió a la trágica jornada del Alto de la Alianza y se retiró por Puno en seguimiento de su jefe. Estuvo luego en la defensa de Lima y cayó herido en la batalla de Miraflores. Algunos días después su nombre figuraba al lado de los de muchos jefes y oficiales que suscribieron el compromiso de no volver a tomar las armas contra Chile. Tal vez fue ese compromiso el que orientó su posterior proceder, ya que, como segundo de Montero, consintió en 1883 la defección de Arequipa.

Volviendo a lo nuestro, el 29 de marzo García Calderón decretó la vigencia de la Constitución de 1860 y ordenó el cese de las autoridades políticas y militares nombradas por la dictadura. Amenazó con juicios y severas penas a todo aquel que se opusiese o trabase esa disposición y dio un plazo de 20 días para el reconocimiento de las nuevas autoridades que anunciaba designar. Bien se entiende que dicho decreto fue impracticable. Pero resultado diferente tuvo otro expedido ese mismo día, por el cual convocó a un Congreso Extraordinario, y fijó el 15 de mayo para el inicio de sus sesiones en la Escuela de Clases de la villa de Chorrillos. Dicho Congreso tendría como objetivos la elección del presidente y vicepresidentes provisorios de la república, y el dictado de disposiciones conducentes a lograr la paz con Chile. Funcionaría sobre la base de los representantes que habían asistido al Congreso de 1879, y se reemplazarían por elección a los diputados y senadores que a esa fecha habían cesado en sus cargos. Para la prensa española, que por medio de corresponsales seguía estos sucesos, la entronización de García Calderón anarquizaba más al Perú y lo ponía al borde de la guerra civil ${ }^{11}$.

Desde el 16 de marzo el nuevo régimen puso en circulación El Orden, como su periódico oficial. Sus directores fueron los clérigos Manuel González de la Rosa y Germán de la Fuente Chávez, lo que desde ya anunciaba su orientación a favor del cese de la guerra. En sus páginas escribieron intelectuales como Carlos Augusto Salaverry, Luis Benjamín Cisneros y Pedro Paz Soldán. Además, reclutaron como redactores a algunos de los que trabajaron en el clausurado diario de Miró Quesada. El Orden fue ante todo

11 La correspondencia fechada en Lima el 30 de marzo fue publicada en La lberia de Madrid, el martes 10 de mayo de 1881. 
un órgano de propaganda, mas no de análisis, y sirvió fundamentalmente para dar a luz los ampulosos documentos emanados del Gobierno de La Magdalena, criticando con acritud el accionar de Piérola, sin poner mientes en falsear, exagerar o tergiversar los hechos, algo común en ambos bandos. Surgió en consecuencia un enfrentamiento mediático entre $E I$ Orden y el Registro Oficial de Junín, uno de los voceros de la dictadura ambulante, polémica que se extendería luego a otros periódicos del interior.

En el Registro Oficial de Junín le cupo al teniente coronel Juan Norberto Eléspuru la tarea de rectificar lo propalado por el diario calderoniano, difícil encargo porque lo que consideraba falsedades eran medias verdades. El Orden difundía las noticias y aun los rumores que a su redacción remitían los opositores del pierolismo en la capital y en el interior, y los había no muy lejos del dictador, en ciudades como Tarma y Cerro de Pasco. Una de las no muy convincentes «rectificaciones» de Eléspuru decía a la letra:

El número 5 de El Orden [...] dice, entre multitud de falsedades, [...] lo que sigue: «Toda la correspondencia que salió de Lima, posteriormente a aquella que llevó el acuerdo del 22 de febrero, fue interceptada por comisarios del exdictador en Chicla». Falso de toda falsedad. La comunicación con la capital, y con los demás pueblos de la república, ni se ha interceptado, ni se ha interrumpido absolutamente por nadie, ni mucho menos por disposición de S. E. el jefe supremo [...] Dice además: «Se había ordenado al señor J. M. Echenique fuera al Cerro de Pasco para imponer a la población un cupo, que debiera ser pagado en barras o moneda sellada, de quinientos mil soles plata». Tal aseveración es igualmente falsa. No se ha dado orden alguna a este respecto al jefe superior político y militar de los departamentos del Centro, y ni éste ni ninguna otra autoridad ha pensado siquiera en semejante cosa [...] Pero también dice El Orden que «los vecinos de Jauja y demás ciudades y pueblos próximos vivían temerosos de actos de violencia, escándalos y nuevas desgracias». Los públicos y reiterados testimonios, tanto de Jauja, como de las ciudades y pueblos inmediatos, son un elocuente mentís a las aseveraciones de la impostura, sugeridos por estudiada aunque inútil malicia. Se ha afirmado también por El Orden que las autoridades nacionales habían prohibido que los ganaderos de Canta bajasen a Lima ganado, para la provisión de la ciudad. Tal noticia es no menor impostura que las anteriores. Ninguna disposición relativa al tránsito de personas o cosas ha sido dictada, y menos respecto a provisión de víveres para Lima. (Registro Oficial de Junín, viernes 11 de marzo de 1881).

No eran desmentidos válidos, ni favorecían a Piérola; por el contrario, demostraban su inacción. Si la guerra continuaba, como había proclamado el dictador al dejar Lima, era lógico que interceptase las comunicaciones en Chicla, estación final de la vía férrea, o que impidiese el 
abastecimiento de la capital donde estaba el grueso del ejército de ocupación. Piérola no hacía ni lo uno ni lo otro, porque su «guerrerismo» fue solo una pose, y muy efímera. Respecto al temor de los vecinos de Jauja y otras ciudades, en realidad existía, y se haría patente poco después con el avance de la expedición chilena del coronel Letelier. Finalmente, a los ricos vecinos de Cerro de Pasco, que era entonces capital del departamento, no les agradaba pagar cupos, mucho menos si eran para la causa patriota; porque este ideal tenía poca cabida en la mayoría de mineros, ganaderos y comerciantes peruanos y extranjeros allí radicados.

Como una prueba del supuesto entendimiento existente entre los chilenos y García Calderón, El Orden reprodujo editoriales de La Actualidad y los hizo suyos (El Orden, martes 10 de mayo de 1881). Por eso, y por publicar muchas noticias carentes de veracidad, mereció esta condena de $E I$ Obrero de Áncash:

Los días de correo son esperados en estas tierras con violencia. Las noticias venidas de Lima y de Huaraz por el último correo se pueden apellidar nuevas risibles, porque ¿cómo no causará risa y más que risa, carcajada tendida, el leer ese inmundo papelucho llamado El Orden, órgano de los intereses calderonistas? (El Obrero de Áncash, miércoles 17 de agosto de 1881).

Otro corresponsal de un diario español en Lima fue más ilustrativo al informar sobre el entendimiento entre chilenos y provisorios: «Los comandantes chilenos han hecho ya algunos servicios muy importantes, aceptados por el señor García Calderón. Puede no ser prudente, en la actualidad, determinar el carácter de esos servicios; pero es bien sabido que el Gobierno provisional de La Magdalena tiene ahora a su disposición recursos respetables» (La lberia, miércoles 15 de junio de 1881).

El Gobierno de La Magdalena se pronunció desde siempre contrario a continuar la guerra. En su discurso de asunción de mando, García Calderón pretendió justificar su oposición a toda resistencia armada anunciando que emprendía las negociaciones de paz, aunque sin mencionar los medios con que contaba para alcanzarla. Para él la continuación de la guerra era imposible:

No debe desalentarnos el triste espectáculo de las catástrofes de nuestra patria — dijo en su discurso del 12 de marzo de 1881—, porque no es el Perú el primer pueblo que pasa por semejantes pruebas; antes bien, otros países más poderosos que el nuestro han perdido una y 10 veces la batalla, pero han sabido detenerse a tiempo para reparar por la paz las ruinas hechas por la guerra. Si esos países se hubiesen empeñado tenazmente en la prosecución de una lucha imposible, habrían llegado a su aniquilamiento (Cáceres, 1921, cap. III, anexo 13). 
Los hechos posteriores lo desmentirían, pues la resistencia fue posible en la prolongada campaña de La Breña, y no necesariamente condujo al aniquilamiento del Perú. García Calderón deslizó argumentaciones realmente desconcertantes, al sostener, por ejemplo, que declarándose derrotado el Perú seguía el ejemplo de los países honrados, tal como entonces anotaron sus partidarios, asumiendo una opinión antes vertida por Mariano Bolognesi ${ }^{12}$ :

El discurso de S. E. fue bueno. Manifestó que los desastres de su patria eran debidos en mucho a la desunión de sus hijos, a las guerras civiles y a las ambiciones ilegítimas de muchos de sus hombres públicos; que la abundancia de riquezas naturales había servido de fomento y de incentivo para esas ambiciones punibles y para olvidar la necesidad del trabajo y de la paz, y que la grandeza de los pueblos no consistía en sus riquezas naturales sino en las virtudes cívicas, en la paz, en la unión y en la laboriosidad de sus hijos. En cuanto a la guerra, expresó que otros países mucho más poderosos habían perdido también batallas decisivas y sufrido los desastres de la adversidad en la guerra, y que devorando sus propias amarguras habían buscado después en la paz y en el orden su nuevo engrandecimiento; que el Perú, en su dolorosa situación actual, no debía hacer otra cosa que seguir el ejemplo de los países honrados (Cáceres, op. cit., cap. III, anexo 12).

Integraron su gabinete el doctor Aurelio Denegri, presidente del Consejo y ministro de Hacienda y Comercio; el coronel Manuel Velarde, ministro de Gobierno, Policía, Obras Públicas y Estadística; el doctor José Miguel Vélez, ministro de Justicia y Culto; el doctor Manuel María Gálvez, ministro de Relaciones Exteriores; y el capitán de navío Camilo Carrillo, ministro de Guerra y Marina. Gustaban de reunirse en el exclusivo Club de la Unión, para departir sobre todo de asuntos económicos y lamentar que la guerra fuese «sostenida con los pocos recursos que aún poseían los hombres de orden ${ }^{13}$. Por ello fue que urdieron planes conducentes a evitar que sus recursos, que no eran pocos, se vieran mermados.

La versión tradicional y oficial de estos hechos ha ocultado el carácter de clase que tuvo el Gobierno de La Magdalena. Para definirlo no hace falta recurrir a los testimonios de sus opositores políticos, que los hubo muy ilustrativos, sino que basta y sobra con la hoja impresa que con el epígrafe

\footnotetext{
12 Bolognesi consideró de locos continuar la resistencia y fue quizá el primero en traer a colación la guerra-franco prusiana para exhortar a los peruanos a aceptar la paz con la cesión territorial que exigía Chile. Su pronunciamiento fue publicado en El Comercio de Guayaquil, el 25 de febrero de 1881.

13 Despacho remitido desde Lima el 31 de marzo y publicado por La lberia de Madrid el martes 10 de mayo de 1881 .
} 
«Al pueblo» hicieron circular los calderonianos en Lima, el 26 de febrero de $1881^{14}$. En este documento se autodefinieron como integrantes de la plutocracia y justificaron su proceder con los mismos argumentos que en todo tiempo han esgrimido las clases dominantes y que pueden condensarse en un solo pensamiento: «Si desaparecen los ricos, no habrá trabajo para los pobres». Salta a la vista que los redactores de esta hoja buscaban poner un dique a la lucha de clases, porque de su lectura se infiere que hubo entonces agitadores sociales incitando a la subversión. Los plutócratas se consideraron víctimas de la guerra, bajo la falsa premisa de que en ella pierden más los que poseen bienes de fortuna que los que solo viven de su trabajo. Y como si no hubiesen sido los directos culpables de la bancarrota del Perú, al que desgraciaron con la sucesión de sus Gobiernos corruptos, adujeron inocencia clamando por la paz que les permitiese preservar o recuperar sus fortunas aduciendo que de ello dependía también el bienestar de los trabajadores:

La capital de la república y todos los pueblos ocupados por el enemigo gimen bajo el yugo del vencedor, que cada día se manifiesta más exigente y amenazador; cierran el comercio, que a esto equivalen los exorbitantes derechos impuestos a los principales artículos de subsistencias; con esto el que sufre más directamente el mal es el trabajador, que no tiene trabajo, que su subsistencia encarece día por día, que su domicilio, por ser más retirado del centro de la población, es violado de todos modos. ¿Tienen la culpa de todo esto los titulados hombres ricos, si todavía los hay, que también sufren el saqueo y destrucción de sus haciendas y casas? Ciertamente que no: la causa de esos males es la guerra, guerra que para nuestra fatalidad no podemos continuar hoy.

Para ellos, «el pueblo trabajador» era una clase y «los ciudadanos», otra. Señalaron que el primero alzaba sin razón su voz de protesta contra los segundos. Y que, debido a la inacción de la masa trabajadora, los «ciudadanos» reasumían el Gobierno para salvar a la patria. Tal se lee en la hoja impresa:

El pueblo trabajador no se movía ni daba señales de vida, a no ser para quejarse de su miseria. Entonces, los ciudadanos, contra los que algunos reclamaban hoy, tomaron la iniciativa de la salvación de la patria, se agruparon e invocando la salvadora garantía de la Constitución, presentaron al pueblo laborioso a un ciudadano de honrosos antecedentes, por su inteligencia, actividad, firmeza y patriotismo,

14 Debemos a Zoila Aurora Cáceres, la hija del jefe de La Breña, el conocimiento de este singular documento que insertó en su obra ya citada, pp. LIX-LXI. 
como candidato digno y capaz de salvarnos de la anarquía y de la angustiosa y agonizante situación en que todos nos encontrábamos.

Había que poner dique a las exigencias del pueblo, porque la libertad tiene un límite, expusieron al mismo tiempo los plutócratas con la siguiente argumentación:

Le hemos dicho al pueblo en todos los tonos que es libre; pero jamás nos hemos preocupado de indicarle la línea donde concluye la libertad y empieza la licencia; le hemos llenado la cabeza con sus derechos, legítimos unas veces, maleados otras por la exageración; pero nunca le hemos trazado sus deberes, ni recomendado su cumplimiento; hemos halagado sus pasiones, para explotarlo en nuestro provecho, creando el espíritu de resistencia a la autoridad legítima, lo que ha llegado a dar por fruto que los pueblos se crean humillados por la violencia; hemos clamado contra los hombres enriquecidos por el trabajo y la economía, señalándolos a la envidia y el rencor, en vez de enseñar que esas riquezas garantizan el jornal y el salario, llevan el óbolo a la casa del pobre, fomentan los establecimientos de misericordia, sostienen el crédito que hace prosperar la industria y abren nuevos capitales y con ellos la abundancia y el bienestar, de que no gozaremos en adelante sino a condición de una cordura desconocida hasta el día y de una reforma radical en nuestras costumbres sociales y políticas (El Orden, sábado 19 de marzo de 1881).

Y refiriéndose a los que hablaban de alzarse contra el Gobierno de los ricos, los plutócratas terminaban su manifiesto con la siguiente advertencia:

¡Conciudadanos virtuosos y laboriosos que vivís del trabajo, no os dejéis engañar por algunos hombres que solo viven del desorden que favorece el robo y el asesinato! Vosotros seréis víctimas por falta de trabajo, si los hombres que han adquirido fortuna la pierden por el saqueo y la violencia. Estos hombres que llamáis ricos tienen intereses comunes con vosotros, y vosotros sin ellos seréis víctimas. Solo aprovecharán del desorden los perversos que siembran la funesta semilla de la discordia.

Cabe preguntarse: ¿influyó esa prédica en la pasividad que mostraría la población limeña en los más de tres años que duró la ocupación chilena? ¿Tuvo más efecto la amenaza hecha por el invasor por medio de su prensa? ¿Pesó más la ausencia del equipo bélico que se requería para que accionasen guerrillas urbanas? Es probable que confluyeran esos factores y otros más, como que Lima, recientemente, había visto correr mucha sangre, durante la represión de la asonada popular que precedió a la entrada de los invasores chilenos. 


\section{La prensa chilena en Lima y los asuntos internos del Perú}

Respecto a la actividad de la prensa chilena en Lima, hemos citado ya al diario La Actualidad, vocero oficioso del ejército de ocupación, cuyo primer número apareció el 20 de enero de 1881, trabajado en los talleres tipográficos donde antes se había impreso El Peruano. El general Baquedano confió su administración a José Isidoro Errázuriz y designó como sus redactores principales a Salvador A. Castro y Luis E. Castro. El administrador retornó a Chile un mes después y lo reemplazó el señor Riquelme. Este periódico reflejó el pensamiento del alto mando chileno, no solo informando sobre la administración del territorio ocupado sino también inmiscuyéndose en las disputas políticas que dividieron a los peruanos, dando su apoyo al régimen provisorio de García Calderón y desprestigiando a la dictadura de Piérola: «El rumbo fijado a La Actualidad desde el primer número [...] [fue] defender los intereses de Chile y formular opinión franca sobre la política interior y exterior del Perú, según contradiga o se armonice con esos intereses» ${ }^{15}$.

Informó asimismo sobre el desarrollo de algunas acciones bélicas, como las que marcaron el inicio de la resistencia en la sierra de Lima. $Y$ consignó también valiosas noticias sobre la otra gran guerra que aquel mismo año sostenía Chile, al exterminar mapuches en sus territorios australes. Precisamente, a principios de 1881 tuvo lugar la matanza de indígenas en la línea de Maitén, tras acoger el presidente Santa María el proyecto de exterminar a los pobladores nativos de la Araucanía. Es erróneo, por tanto, llamar araucanos a los chilenos que invadieron el Perú; su clase dominante era blanca, de genes españoles, ingleses y alemanes, principalmente, y su pueblo era un conglomerado de mestizos a los que los primeros llamaban despectivamente «rotos». Estos no se consideraban para nada indígenas y habían asimilado de sus patrones una actitud racista; en los peruanos que habitaban la costa, amén de negros y zambos, ellos vieron «cholaje» y en las serranías solo «indios», pasibles de ser aniquilados como los mapuches. Promediando ese año el Ejército chileno perpetró un «malón general» considerando la frontera austral como escenario de entrenamiento para sus acciones en la sierra del Perú. Sobre la resistencia mapuche, el periódico argentino El Imparcial publicaba a finales de marzo el siguiente despacho:

Los indomables araucanos continúan haciendo una guerra implacable a Chile. Últimamente han ocupado una extensa línea en la

15 Volante firmado por Errázuriz y Riquelme, imprenta de La Actualidad, calle de la Rifa 58, Lima. 
frontera, y en sus excursiones al territorio chileno cometen mil atrocidades: incendian las mieses y las fincas, entran en las poblaciones a sangre y fuego y atacan a las fuerzas del ejército. Si a eso se agrega las deserciones en la tropa expedicionaria chilena, que son numerosas, se comprenderá cuán grave y crítica es la situación de los pueblos fronterizos [...] Un ejército de 3000 hombres, al mando del general Villegas, después de recorrer las pampas combatiendo a los indios, se ha situado en la frontera de Chile, en expectativa de los sucesos que se desarrollan al otro lado de los Andes ${ }^{16}$.

La guerra contra los indígenas, por aquel tiempo, no solo se desarrollaba en Chile, sino también en Argentina y Uruguay. Por aquellos años, los hacendados llegaron a pagar buenas sumas de dinero por cada cabeza de indígena muerto. Imperó en la región la abominable prédica de Domingo Faustino Sarmiento, quien anhelaba el exterminio de los «indios asquerosos» ${ }^{17}$. Sarmiento se anticipó al general yanqui Philip Henry Sheridan, exterminador de las naciones indígenas de las Grandes Llanuras de Norteamérica y autor de la espantosa frase: «Los únicos indios buenos que vi fueron los indios muertos» ${ }^{18}$.

La Actualidad llegó a sacar ciento siete números y cesó la publicación el 27 de mayo de 1881 por orden expresa de Patricio Lynch, no porque incumpliese los propósitos que determinaron su aparición, sino porque las máquinas y los materiales tipográficos fueron embarcados para Chile como botín de guerra (La lberia, jueves 14 de julio de 1881). Para entonces, el general Baquedano se había embarcado ya de regreso a Chile y dejado al general Lagos como jefe interino del ejército de ocupación hasta que, en definitiva, el mando supremo de Chile en el Perú fue asumido por el contralmirante Patricio Lynch, a partir del 16 de mayo de 1881.

16 Despacho reproducido en La Vanguardia de Barcelona, el sábado 23 de abril de 1881. 17 Y a pesar de eso, a Faustino Domingo Sarmiento, presidente de la República argentina de 1868 a 1874, se le considera "el maestro de la patria". En el diario El Progreso, el 27 de setiembre de 1844, Sarmiento había escrito lo siguiente: «¿Lograremos exterminar a los indios? Por los salvajes de América siento una invencible repugnancia sin poderlo remediar. Esa calaña no son más que unos indios asquerosos a quienes mandaría colgar ahora si reapareciesen. Lautaro y Caupolicán son unos indios piojosos, porque así son todos. Incapaces de progreso. Su exterminio es providencial y útil, sublime y grande. Se los debe exterminar sin ni siquiera perdonar al pequeño, que tiene ya el odio instintivo al hombre civilizado». Este desafortunado discurso fue reproducido en El Nacional, el 25 de noviembre de 1876. Por ello ha merecido Sarmiento dura condena y tal vez severísima en extremo fue la pronunciada el 2014 por el ministro de Defensa de la República de Uruguay, Eleuterio Fernández Huidobro, quien lo llamó «grandísimo hijo de puta». Claro que Vargas Llosa intervino para explicar (por no decir justificar) lo que quiso decir Sarmiento. Para el caso se recomienda la lectura del ensayo "Sobre indios, afroamericanos y los racismos de Sarmiento», de Elizabeth Garrels, 1997, pp. 99-13.

18 «The only good Indians I ever saw were dead». Esta frase la consignó Edward S. Ellis en su libro The History of Our Country: From the Discovery of America to the Present Time, «que se publicó por vez primera en 1895 y alcanzó gran difusión posteriormente» (Wolfang Mieder, «El mejor indio es un indio muerto», Paremia, nro. 10, 2001, pp. 49-56). 
En su primer editorial La Actualidad había anunciado sin tapujos, aunque con lenguaje engañoso, que azuzaría las pugnacidades entre peruanos: «La política interna del país no es, sin duda, el resorte de esta publicación. Ha de sernos forzoso, sin embargo, abordar este terreno cada vez que así lo requiera el interés que para nosotros es supremo y siempre que esté de por medio la gran causa de la reorganización del Estado peruano» (La Actualidad, 20 de enero de 1881). Este periódico intervino a fondo en las disputas internas del Perú y al atacar a Piérola provocó la airada protesta de su secretario de Gobierno, Aurelio García y García, quien en una circular fechada en Jauja el 1 de marzo y dirigida al cuerpo diplomático, denunció las imposturas y difamaciones propaladas por La Actualidad, aunque cuidándose de no citarla con nombre propio. Copiamos aquí el extracto pertinente:

Perseverante el Gobierno chileno en sus designios ya manifestados, de completa ruina del Perú, ha sido su más constante empeño, después de la ocupación de Lima y Callao, el 17 de enero último, el promover toda clase de disensiones intestinas. Con este propósito ha establecido en la primera ciudad un periódico semioficial, que, tirado en las prensas del Estado, se ocupa, desde su inauguración, en esparcir todo género de imposturas, difamar a nuestros hombres públicos, desacreditar los principios que gobiernan la sociedad esforzándose, además, artificiosamente, en persuadir que no existe un Gobierno, a pesar de que el de S. E. el jefe supremo cuenta con la obediencia de la nación entera, sin exclusión de una sola aldea (Registro Oficial de Junín, viernes 4 de marzo de 1881).

A decir verdad, la dictadura era el único Gobierno aceptado en casi todo el Perú19 y si los chilenos la desconocieron fue para dar cauce al Gobierno de La Magdalena, total hechura suya, según señaló La Actualidad. Tomando esto a sorna, Palma escribió a Piérola:

La Actualidad tuvo la condenada ocurrencia de estampar editorialmente que el Gobierno del señor don Francisco era hechura exclusivamente chilena y que los chilenos darían palo y palo al peruano que no lo acatase y otras boberías de este jaez. García Calderón les dijo que eso no era lo convenido, y renunció a la presidencia ante los 20 caballeros que componen la junta directiva del club (aquí Palma se refiere al club civilista). Estos caballeros le contestaron que no rasgase sangre por tan poco, que tuviese cachaza y que ellos se

19 «Lima, 29 de marzo de 1881. En el Perú reina gran anarquía. El nuevo presidente provisional, señor García Calderón, sigue gobernando el pueblo llamado La Magdalena, que tiene 50 vecinos, porque en el resto de la república gobierna Piérola», escribía desde Lima el corresponsal de La Vanguardia de Barcelona, despacho que se publicaría el 9 de mayo de aquel año. 
encargaban de conseguir que La Actualidad explicase sus conceptos en términos que bastaran para desvanecer escrúpulos de monja [...] Y, en efecto, La Actualidad dio explicaciones y de ellas resultó que lo roto era peor que lo descocido. La Actualidad remachó el clavo, porque dijo: «Dejémonos de candideces. El papel de Chile en esta comedia va a ser el del loquero que emplea la camiseta de fuerza para hacer entrar en vereda a tirios y troyanos». Lo razonable era presumir que después de este segundo editorial insistiría en la renuncia. Pues nada de esto. Se quedó tan fresco y se dio por satisfecho. Dos días estuvimos con el credo en la boca y encendiendo lamparitas, temerosos de que García Calderón hubiera tomado la cosa por lo serio. Mucho me temí que a la boca del horno se quemara el pan y nos quedáramos sin presidente (Ricardo Palma, 1979, pp. 24-29).

Ciertamente, La Actualidad, dando cuenta de soterradas protestas en Lima por el encumbramiento de García Calderón, exigió de este severidad para reprimirlas y anunció que Chile no consentiría variaciones en la nueva situación planteada, con lo que tácitamente daba a entender que la subordinaba.

La falta de respeto a lo que la mayoría ha sancionado y la rebelión incesante contra la autoridad constituida o por constituirse, han sido antiguos achaques y antiguos principios de disolución del Estado peruano. El Gobierno del señor García Calderón faltaría a su carácter de iniciador de una nueva era en la política del país, si comenzase gastando peligrosa tolerancia con las tendencias que han causado la ruina de casi todos sus antecesores. En cuanto a la autoridad militar chilena, puede anunciarse con seguridad que ella no mirará con ojo benigno el propósito y la pretensión de trastornar los cimientos recién establecidos del edificio constitucional, y que no tolerará que se haga retroceder al Perú en la marcha hacia un desenlace pacífico de la conciencia que amenaza consumir sus últimos elementos de vida y prosperidad. La autoridad chilena posee recursos eficientes para amparar la obra de reorganización y pacificación en que se hallan empeñados millones de buenos ciudadanos, y es indudable que empleará esos recursos, sin vacilación y sin consideraciones, contra los perturbadores del orden de cosas establecido en esta capital [...] y si la celebración de la paz tiene a esta hora, en el Perú, enemigos, la ley marcial funcionará hasta reducirlos a la impotencia y al sometimiento (La Actualidad, 25 de febrero de 1881).

Leyendo ese editorial se entiende que Palma considerase la posibilidad de una renuncia de García Calderón, quien soportó trato tan indigno consciente de que su único apoyo era precisamente el ejército de ocupación. Se atrevió a una tibia protesta, pero con ello solo consiguió una nueva y mayor humillación, pues La Actualidad publicó, casi en son de burla, esta degradante nota aclaratoria: 
Los consejos dados al señor García Calderón, de empuñar las riendas del Gobierno con la energía propia de la situación que trata de dominarse, no han tenido otro móvil que apoyar su naciente Gobierno, como opinión de hombres que deben ver organizarse algo serio y que responda a las necesidades de la violenta crisis por la que atraviesa el Perú. El Gobierno de Chile no ha intervenido ni intervendrá jamás en la formación de tal o cual Gobierno, porque teniendo nociones muy claras de sus deberes, respeta el derecho que asiste a los ciudadanos del Perú para constituirse de la manera que más les convenga. Esto no obsta, sin embargo, para que La Actualidad, que representa la política chilena, formule opiniones y preste el apoyo de su palabra, cada vez que lo crea conveniente a los intereses de Chile [...] En ese sentido obrará La Actualidad siempre que se lo aconsejen los intereses de Chile, prescindiendo completamente de los partidos que forme la política peruana, a los cuales no ha tomado ni tiene que tomar en cuenta [...] Candidez sería pensar lo contrario y que a las barbas del ejército de ocupación se perturbara el orden público, revolviéndose las aguas contenidas por poderoso dique (La Actualidad, 26 de febrero de 1881).

Si García Calderón no tuvo en mente renunciar fue precisamente porque estaba convencido de que podía negociar la paz con Chile sin la cesión de Tarapacá, a través del pago de una crecida indemnización de guerra con el capital que pensaba obtener del Crédit Industriel et Commercial, a cambio de una importante participación en la explotación de las riquezas salitreras, proyecto que solo podía encauzar con la mediación norteamericana e, incluso, con la intervención armada de esta potencia. Desde sus inicios, el Gobierno de La Magdalena contó con la simpatía de Estados Unidos, cuyo embajador en Lima, Isaac B. Christiancy, estuvo «muy estrechamente vinculado a la aristocracia guanera y salitrera» (Roel Pineda, 1986, p. 260). Por esos días, preocupados solo de no ver afectados sus intereses, voceros de la plutocracia no tuvieron reparos en expresar su anhelo de que el Perú fuese anexado a Estados Unidos, o, cuando menos, colocado bajo su protectorado. El embajador escuchó con entusiasmo ese parecer $y$, secundándolo con inusitada vehemencia, lo trasmitió de inmediato al secretario de Estado, William M. Evarts, juzgando de urgencia la intervención norteamericana porque, en su entender, lo que estaba en disputa realmente era el dominio imperialista en el Pacífico. Su carta, fechada en Lima el 4 de marzo de 1881, contenía este parágrafo:

La gran mayoría de todas las clases sociales del Perú siente un afecto muy grande por los Estados Unidos y un fuerte odio por Inglaterra [...] Mi conclusión es que el único medio eficaz para que los Estados Unidos dominen el comercio del Perú y eviten el predominio británico es intervenir activamente obligando a los beligerantes a un arreglo 
de paz en términos razonables o gobernar el Perú por medio de un protectorado o de una anexión. Estos proyectos me han sido sugeridos a menudo y fuertemente, por peruanos, y encuentro que el clero católico está a favor de la anexión. En una votación, tres cuartas partes o cuatro partes, también lo apoyarían. Cincuenta mil ciudadanos emprendedores de los Estados Unidos dominarían a toda la población y harían al Perú totalmente norteamericano. Con el Perú bajo el Gobierno de nuestro país, dominaríamos a todas las repúblicas de Sudamérica y la Doctrina Monroe llegaría a ser una realidad (publicado por Querejazu Calvo, 1992, p. 505).

El ministro de Relaciones Exteriores de La Magdalena, confiando en el apoyo de la gran potencia, convocó a su despacho a Mr. Christiancy para comunicarle que el Perú se ponía bajo la protección norteamericana. El embajador consultó el asunto con Washington sin obtener aprobación. Pero el Gobierno del presidente Rutherford B. Hayes hizo saber que apoyaría al Perú en la preservación de su integridad territorial, siempre que le fuese posible pagar una considerable indemnización de guerra. Como queriendo reforzar esa opinión, el Gobierno norteamericano incrementó su flota en el Pacífico y rechazó toda injerencia europea, especialmente la británica o francesa en el diferendo peruano-chileno. A las claras se podía inferir que la guerra la disputaban también las potencias imperialistas. Finalmente, el consenso internacional se declaró neutral, lo que en la práctica significó consentir la expansión chilena. A nivel oficial, el Gobierno de La Magdalena solo fue reconocido por Costa Rica, Uruguay, Suiza, Dinamarca y Estados Unidos.

Por otro lado, sabido es que los chilenos impusieron a los potentados de la capital un cupo ascendente a un millón de pesos mensuales, y que esa contribución se hizo efectiva con puntualidad mientras duró el Gobierno de La Magdalena. Pero no se crea que los Canevaro, Derteano, Roca y Boloña, Cox, La Torre, Silva Santisteban, Swayne, Tenaud, Rubio, Pflucker, Laos, Barreda, Químper, Porras, Riva Agüero, Goyeneche, Pardo, Canaval, Diez Canseco, Carrillo y Albornoz, Basagoitia, Elguera, Bresani, García y García, Calderón, Cisneros, Correa y Santiago, Irigoyen, Ayulo, Candamo y Cantuarias mermaron algo de sus fortunas personales con ello. Porque experimentados en toda suerte de argucias legales, estos señorones lograron que García Calderón consiguiese esa suma mediante un empréstito nacional. La idea surgió del propio ministro de Hacienda, sumiso con los chilenos, que ofreció garantías carentes de valor y aumentó la deuda peruana por salvar a 50 propietarios, conforme anotó el corresponsal de un diario español: 
El señor Denegri aceptó el derecho de los chilenos a imponer contribuciones, y sugirió la idea de un empréstito al $6 \%$ de interés que representara el tipo actual de los cambios y que fuera redimido con el producto de la venta de los sellos y el $30 \%$ de los derechos de la aduana del Callao. Cuando hubo terminado, el señor Dubois, jefe de la casa de Graham, Rowe y Compañía pidió que los extranjeros ayudaran a los peruanos en sus dificultades, y encabezó la lista con una fuerte suma. El señor Gildemeister se suscribió después, y de esa manera pudo el Gobierno pagar al día siguiente como \$250 000 en dinero metálico. Se comprometió a entregar el resto al cabo de un mes. El general Saavedra aceptó [...] La garantía ofrecida por el señor Denegri carece de valor; la aduana del Callao está, y quizá permanecerá por mucho tiempo, en poder de los chilenos. Si el Gobierno hubiera ofrecido como garantía sus propiedades inmuebles además de las que pertenecen a las 50 personas cuya ruina se trataba de evitar, se habría conseguido el total de la suma. Pero el señor Denegri ha adoptado la misma conducta de sus antecesores en la cartera de Hacienda y aumentado la deuda flotante inconvertible. De esta manera ha sucumbido la fuerza vital del Perú: bonos extranjeros creados y nunca redimidos; bonos internos emitidos, no pagados primero, consolidados después y olvidados más tarde; documentos de diversos tamaños y de distintos colores, pero de ningún valor; bonos de aduana, certificados de nitrato, etc. La lista es larga; sin embargo, hay ya que aumentarla. Cómo se pagará siquiera una parte es lo que no pueden decir los que conocen la actual situación del Perú. Eso sin tener en cuenta los millones y millones de billetes de los bancos que tanto han contribuido a la ruina del país, ni los incas de papel que D. Nicolás de Piérola inventó para consumar las dificultades rentísticas, invención que le ha costado la disminución rápida de su popularidad (La lberia, martes 10 de mayo de 1881).

El 14 de marzo dicho empréstito fue autorizado por un decreto especial, cuyas condiciones fueron intereses del $6 \%$ anual y amortización a la par. Bien se aprecia que se trató de un pingüe negocio. Convocados por el Gobierno los grandes comerciantes de la capital, en buena parte extranjeros asociados con los «hijos del país» — como a sí mismos se llamaron los oligarcas peruanos-, aceptaron de buena gana efectuar el préstamo, que habría de ser puntualmente reconocido por los Gobiernos posteriores. Ello agravó «el proceso de la deuda nacional, que creció notablemente con los intereses que se acumularon», según denunció Zoila Aurora Cáceres (op. cit., p. 130). Además, García Calderón obtuvo un préstamo del Banco de Londres, México y Sudamérica, y emitió billetes, lo que dio motivo al pierolismo para denunciar un escandaloso fraude en perjuicio del Estado (La Patria, 22 de agosto de 1881). 
Para mediados de junio, el Magdaleno había favorecido con creces las exigencias económicas del ejército de ocupación, tal y como lo informaba la prensa española: «El presidente semirreconocido del Perú, señor García Calderón, ha pagado los 8 millones de soles papel, equivalentes a 800000 pesos plata, que quedaban por pagar de la contribución de guerra impuesta a Lima». Además, «los chilenos han vendido a varios comerciantes ingleses 50000 toneladas de guano de las islas de Lobos, al precio de 35 pesos fuertes tonelada» (El Globo, jueves 21 de julio de 1881).

Pero el capital necesario para ofrecer a Chile una indemnización de guerra se negociaba con el Crédit Industriel et Commercial, grupo financiero francés con el que el Estado peruano, a poco de iniciada la guerra, suscribió un contrato que le cedía el privilegio para la explotación monopólica del guano de covadera y algunas oficinas salitreras. Piérola, al asaltar el poder, anuló ese contrato por mandato de Dreyfus, pero García Calderón lo resucitó en 1881. Buenaventura Seoane, historiador de la época, refiere que el Gobierno de La Magdalena celebró un contrato con el Crédit Industriel de París, ratificando por conducto del comisionado extraordinario doctor Francisco Rosas el que este y el ministro en Francia don Juan M. Goyeneche, habían acordado durante la administración del general Prado y que no se cumplió por haberlo desaprobado el dictador don Nicolás de Piérola. Este contrato permitía al Gobierno provisorio, mediante la venta y garantía del guano y del salitre, el servicio íntegro de la deuda externa y el pago de una indemnización de 80 millones (Buenaventura Seoane, op. cit., p. 125).

Otra versión señala que el Crédit Industriel ofreció pagar el total de la indemnización que exigía Chile a cambio de que el Gobierno peruano le entregara todas las salitreras. Y habría presentado también otra alternativa: el pago de la indemnización a cambio de que el departamento de Tarapacá le fuese entregado en concesión. Además, ofreció movilizar a una potencia extranjera contra Chile si este país no aceptaba la indemnización sin cesión territorial. Esa potencia extranjera no era otra que Estados Unidos, con cuyo Gobierno tenía el Crédit una estrecha vinculación, a través del abogado neoyorkino Robert E. Randall. Tratándose de un negocio en vasta escala, había interesado al propio secretario de Estado norteamericano, Mr. Evarts; y para neutralizar a los acreedores europeos convirtió al presidente de Francia, Jules Grevy, nada menos que en socio del Crédit. «Efectuados los arreglos del caso, el Crédit Industriel firmó un acuerdo secreto con García Calderón, cuando corría el mes de marzo de 1881» (Roel Pineda, op. cit., p. 263). Así fue como el civilismo se entendió con el Crédit, que se comprometió a respetar los derechos de los inversionistas salitreros. Para finiquitar los detalles del negocio en Estados Unidos se 
comisionó a Federico Elmore, nombrado para el efecto con el carácter de agente confidencial, toda vez que el negociado era secreto. La situación se mantuvo sin variantes incluso luego del cambio presidencial en Estados Unidos, que tuvo lugar a mediados de ese año. El presidente Hayes fue relevado por James Garfield, y el secretario de Estado Evarts dejó su puesto a James G. Blaine. Enterado este del negociado, solicitó un informe a Elmore, quien, advirtiendo su interés, le propuso integrarse al Crédit como socio. Aceptó Blaine y nombró como nuevo embajador en el Perú al general Stephen A. Hurlbut, quien al asumir una posición favorable al Perú en realidad velaba por el gran negocio. Queda así demostrado que el tantas veces mentado patriotismo de García Calderón no fue otra cosa que la desesperada defensa de los intereses económicos de su grupo. Así lo vieron varios de sus contemporáneos, y no solo sus rivales pierolistas. El Gobierno de La Magdalena pretendió una paz no tanto para defender los intereses del país, sino por poner a buen recaudo la fortuna del grupo económico al que representaba. A los civilistas se les dio el apodo de «argolleros» por pertenecer a un cerrado círculo de burgueses apátridas, que carecieron de todo escrúpulo en la consecución de sus fines. Testimonio incontestable de tal aseveración puede hallarse en la correspondencia que por aquel tiempo remitió el diplomático peruano José Antonio de Lavalle a su amigo y colega chileno Ambrosio Montt, con este acápite:

Dudo que lleguemos a la paz —le dijo—, y no porque tu Gobierno [el de Chile] no la desee y anhele, sino por los mil y mil obstáculos que ha de ofrecer para llegar a ella un grupo de negociantes que prefieren mil veces la ruina y la desaparición de su país, a que ese país exista si no ha de ser objeto de su explotación perpetua. Aludo, sin embozo ni rodeos, al que acaudilla tu cliente, García Calderón (publicada por Valencia Avaria, 1970, p. 11).

El que fuera presidente de la Compañía Salitrera del Perú no aceptó la cesión de Tarapacá a Chile, pero negoció su entrega al Crédit Industriel o a Estados Unidos, pensando que esta era la única manera de salvar las inversiones del grupo al que representaba. Al respecto, Carlos Vicuña Fuentes ha escrito:

Las negociaciones con García Calderón tomaron un camino tortuoso. Un grupo de desvergonzados especuladores norteamericanos y franceses intentaron apoderarse del guano del Perú ubicado en los territorios ocupados por Chile, mediante el apoyo del gabinete de Washington, para lo cual pretendieron que este obligase a Chile a aceptar una indemnización pecuniaria en vez de los territorios que exigía (Vicuña Fuentes, 1975, p. 48). 
Se equivocan por ello autores como Peter J. Sehlinger, quien al hablar del asunto desconoce, oculta o soslaya sus detalles, elogiando en García Calderón «su coraje y su moral cívica» (citado por Sehlinger, 1987). Parece que los chilenos ignoraron el negociado sobre las salitreras de Tarapacá hasta mucho después de la llegada de Hurlbut. Al descubrirlo, amenazaron con hacer públicos sus detalles, y entonces fue que la gran potencia, para contener el escándalo internacional, varió radicalmente su posición y se entendió con Chile. Ese descubrimiento fue factor decisivo para que Chile pusiese término a la farsa de La Magdalena, el 29 de setiembre de aquel anárquico 1881 .

\section{FUENTES PERIODÍSTICAS}

El Comercio, Guayaquil 1881

El Globo, Madrid, 1881

El Orden, Lima, 1881

El Obrero de Áncash, Huaraz 1881

La Actualidad, Lima, 1881

La lberia, Madrid, 1881

La Patria, Ayacucho, 1881

La Vanguardia, Barcelona, 1881

Registro Oficial de Junín, Jauja, 1881 


\section{REFERENCIAS BIBLIOGRÁFICAS}

Alba Herrera, A. (1997). Huaras. Historia de un pueblo en transformación. Caras: Ediciones El Inca.

Cáceres Moreno, Z. A. (1921). La Campaña de La Breña. Lima: Imprenta Americana.

Compañía del Salitre del Perú (1912). El crédito de la Compañía Salitrera del Perú. Lima: Librería e Imprenta Gil.

Garrels, E. (1997). Sobre indios, afroamericanos y los racismos de Sarmiento. Revista Iberoamericana, vol. LXIII, nros. 178-179, pp. 99-13.

González Prada, M. (2004). Propaganda y ataque. Baltimore: Loyola College. Guerrero, J. (1975). La guerra de las ocasiones perdidas. Lima: Editorial Milla Batres.

Mieder, W. 2001. El mejor indio es un indio muerto. Paremia, nro. 10, pp. 49-56.

Palma, R. (1979). Cartas a Piérola sobre la ocupación chilena en Lima. Lima: Editorial Milla Batres.

Querejazu, R. (1992). Guano, salitre, sangre. La Paz: Editorial Juventud.

Roel, V. (1986). El Perú en el siglo XIX. Lima: Editorial Idea.

Sehlinger, P. J. (1987). Páginas trágicas de la historia peruana: Las cartas del presidente cautivo Francisco García Calderón desde Chile en 1882. Fénix.

Seoane, B. (1903). El biógrafo americano. Lima: Librería e Imprenta Moreno.

Valencia, L. (1970). Cartas de José Antonio de Lavalle y Arias de Saavedra. Boletín de la Biblioteca Nacional del Perú.

Vicuña, C. (1921). La libertad de opinar y el problema de Tacna y Arica. Santiago: Imprenta, Litografía y Encuadernación Selecta. 